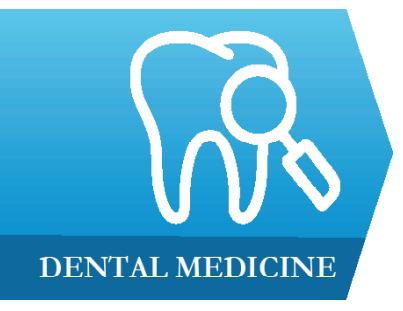

1) Department of Oral and Maxillofacial Surgery, Pacific Dental College and Hospital, Udaipur, Rajasthan, India

2) Department of Prosthodontics, Darshan Dental College, Udaipur, Rajasthan, India
DOI: $10.15386 / \mathrm{mpr}-1195$

Manuscript received: 24.09 .2018

Received in revised form: 07.12.2018 Accepted: 11.01.2019

Address for correspondence: khandelwal.pulkit22@gmail.com

\title{
Miniplate removal in operated cases of maxillofacial region in a dental institute in Rajasthan, India
}

\author{
Pulkit Khandelwal ${ }^{1}$, A Bhagavandas Rai ${ }^{1}$, Bipin Bulgannawar ${ }^{1}$, \\ Nilay Vakaria ${ }^{1}$, Hemal Sejani ${ }^{1}$, Neha Hajira ${ }^{2}$
}

\begin{abstract}
Background. The long term management of miniplate fixation osteosynthesis remains debatable and controversial with few authors advocating routine removal of the miniplates after 3-6 months of placement, while others recommend retention of the miniplates unless their removal is clinically indicated.

Objective. The aim was to study the incidence, indications, time gap, role of metallic composition and site of removal of miniplates in operated cases of maxillofacial region over a two-year period.

Methods. Patients undergoing removal of miniplates over 2-year period were studied and evaluated regarding the number of miniplates removed, time gap present between fixation and removal of miniplates, indications for removal, metallic composition of miniplates removed, sites of removal and complications. Correlations between indications for miniplate removal based upon time gap, metallic composition, age group and number of miniplates present were determined using Chi-square test. Correlation between metallic composition of miniplate and time gap was also determined using Chi-square test.
\end{abstract}

Results. The miniplates were removed in 20 patients (16 males and 4 females). Most common indication for removal was infection (45\%). Forty-five percent of the patients underwent miniplate removal within 1 year of placement. Thirty-four miniplates and 118 screws were removed. The correlation between indications for miniplate removal and time gap was found to be statistically significant $(\mathrm{P}=0.04)$.

Conclusion. Most of the hardware removal is performed subsequent to complications associated with hardware and local factors play more important role than metallic composition. Routine asymptomatic miniplates do not require removal and is not recommended.

Keywords: fixation, fracture, infection, miniplate, trauma

\section{Introduction}

Open reduction and internal fixation is standard of care for the management of maxillofacial fractures following trauma. Anatomic reduction and meticulous fixation of fracture site offers better pain alleviation, early functional recovery, avoiding intermaxillary fixation, a more rapid return to normal function, reduced incidence of weight loss and improved early mouth opening [1]. However, the routine use of internal hardware for fixation is not associated without disadvantages and complications [2]. Pioneers of maxillofacial fracture fixation advocated routine removal of the hardware after 3 months of fixation. At an average of 4 to 6 weeks, the hardware becomes obsolete, once fracture has healed and bony union is achieved $[3,4]$.

The most commonly reported indications for maxillofacial hardware removal include infection at the site of surgery and/or hardware extrusion or exposure. Murthy and Lehman reported that most infections after fixation surgery for maxillofacial trauma occur in the mandible and are the major cause of miniplate removal [5]. Studies have reported various values for the removal rate of miniplates, ranging from $7 \%$ to $33.8 \%$. Some researchers recommend removal in general, while others do not recommend removal unless clinical symptoms or complications occur. Clear evidence for such a recommendation has not yet been established. 


\section{Aim of the study}

The present study analyzed the incidence, indications, time gap, metallic composition of miniplates removed and site of removal of miniplates over a two-year study period in operated cases of maxillofacial region.

\section{Materials and methods}

From January 2015 to December 2016, twenty patients reported to the department with clinical symptoms or complications at previously operated site, indicated for miniplate removal. Ethical approval was obtained from the Institutional Review Board. Informed consent was taken from all patients. Data collected comprised age, gender, reason for removal of miniplates, site of removal, length of time between surgery and removal of the miniplate, number of miniplates removed, metallic composition of miniplates and intra-operative and post-operative complications following miniplate removal. The reasons for removal were classified into the following categories: patient's request for removal; infection; pain without signs of infection; asymptomatic miniplate exposure; pediatric trauma; prosthetic rehabilitation; and others. The site of miniplate removal included mandible and midface. Correlations between indications for miniplate removal based upon time gap, metallic composition, age group and number of miniplates present were determined using Chi-square test. Correlation between metallic composition of miniplate and time gap for removal was also determined using Chi-square test.

\section{Results}

Over two years, 20 patients underwent miniplate removal. There were 16 males $(80 \%)$ and 4 females $(20 \%)$, with an average age of approximately 32.5 years (range, 4 - 65 years) (Table I). Miniplates were removed in 16 cases $(80 \%)$ from mandible and four cases $(20 \%)$ from midface region. In the mandible (16 cases), body and symphysis region were most commonly involved (5 cases each $31.25 \%$ ) followed by angle region $(18.75 \%$ ), and condyle $(6.25 \%)$. However, multiple sites were involved in only 2 cases $(12.5 \%)$ (Table II).

Table I. Age distribution (20 patients).

\begin{tabular}{l|c|c}
\hline Age (year) & Case (n) & $\%$ \\
\hline $\mathbf{1 - 2 0}$ & 3 & 15 \\
$\mathbf{2 1 - 4 0}$ & 12 & 60 \\
$\mathbf{4 1 - 6 0}$ & 2 & 10 \\
$\geq \mathbf{6 0}$ & 3 & 15 \\
Total & $\mathbf{2 0}$ & $\mathbf{1 0 0}$
\end{tabular}

Table II. Site of miniplate removal from mandible (16 patients).

\begin{tabular}{l|c|c} 
Site & Case (n) & \% \\
\hline Symphysis & 5 & 31.25 \\
Body & 5 & 31.25 \\
Angle & 3 & 18.75 \\
Condyle & 1 & 6.25 \\
Multiple sites & 2 & 12.5 \\
Total & $\mathbf{1 6}$ & $\mathbf{1 0 0}$
\end{tabular}

Total 34 miniplates and 118 screws were removed in these 20 patients. Out of 34 miniplates removed, stainless steel and titanium material shared equal percentage (17 miniplates in 10 patients in each category). Out of 118 screws, $62(52.54 \%)$ were stainless steel and $56(47.46 \%)$ were titanium. There were 9 cases $(45 \%)$ in which the miniplates were removed due to infection (Figure 1) and in 6 cases $(30 \%)$, miniplates were removed due to complaint of pain without any sign of infection (Figure 2). Prosthetic rehabilitation (Figure 3a), asymptomatic miniplate exposure (Figure $3 \mathrm{~b}$ ) and patient request (Figure 3c) needed miniplate removal in 1 case each $(5 \%)$. One patient was a 4 years old child (Figure $3 \mathrm{~d}$ ) and in one patient, malunion subsequent to inadequate reduction led to deranged occlusion (Figure $3 \mathrm{e}$ ) requiring miniplate removal (Table III).

Table III. Indication for miniplate removal (20 patients).

\begin{tabular}{l|c|c|}
\hline Reason for plate removal & Case (n) & \% \\
\hline Patient's demand & 1 & 5 \\
Pediatric trauma & 1 & 5 \\
Pain & 6 & 30 \\
Prosthetic rehabilitation & 1 & 5 \\
Deranged occlusion & 1 & 5 \\
Infection & 9 & 45 \\
Asymptomatic exposure & 1 & 5 \\
Total & $\mathbf{2 0}$ & $\mathbf{1 0 0}$
\end{tabular}

Three cases $(15 \%)$ each were performed within 3 months, within 3 to 6 months and within 6 to 12 months, 5 cases $(25 \%)$ within $1-2$ years and 6 cases $(30 \%)$ in which removal was performed after more than 2 years of first surgery (Table IV). There was a higher incidence of miniplate removal (9 cases $-45 \%$ ) within one year of first surgery. Removal of miniplate was performed within 3 months in three cases (Figure 1i, 3d, 3e) because of infection involving bone, pediatric care and malunion subsequent to inadequate reduction in one case each, respectively. One case was operated case of orthognathic surgery in which miniplate from zygomatic buttress was removed due to pain subsequent to miniplate exposure at the site (Figure 2d). Among these 20 cases, there were 9 cases in which miniplate fixation was done at other sites also but were not indicated for removal. There was no incidence of any post-operative complications like pain, swelling, paresthesia, bleeding, infection, etc. The preoperative physical symptoms were relieved following miniplate and screw removal.

Table IV. Time between miniplate insertion and miniplate removal (20 patients).

\begin{tabular}{l|c|c} 
Time & Case $(\mathbf{n})$ & $\mathbf{\%}$ \\
\hline Less than 3 months & 3 & 15 \\
3- 6 months & 3 & 15 \\
6 - 12 months & 3 & 15 \\
1 - 2 years & 5 & 25 \\
More than 2 years & 6 & 30 \\
Total & $\mathbf{2 0}$ & $\mathbf{1 0 0}$
\end{tabular}



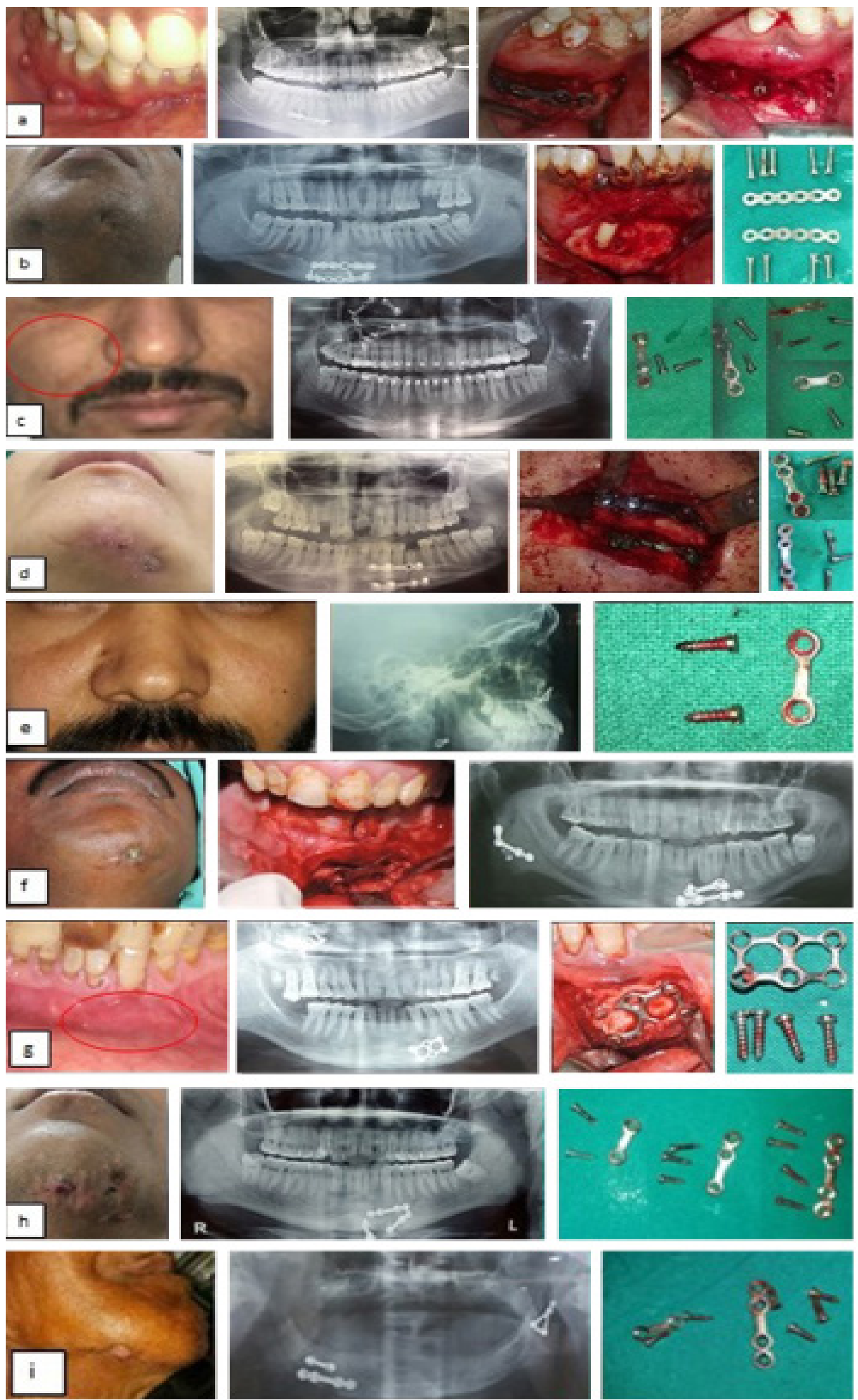

Figure 1. Nine cases of infection leading to miniplate removal. a), b), d), g) - Infection due to tooth damage; c), e), f), h) - Infection subsequent to screw loosening; i) - Infection in edentulous mandible. 


\section{Dental Medicine}
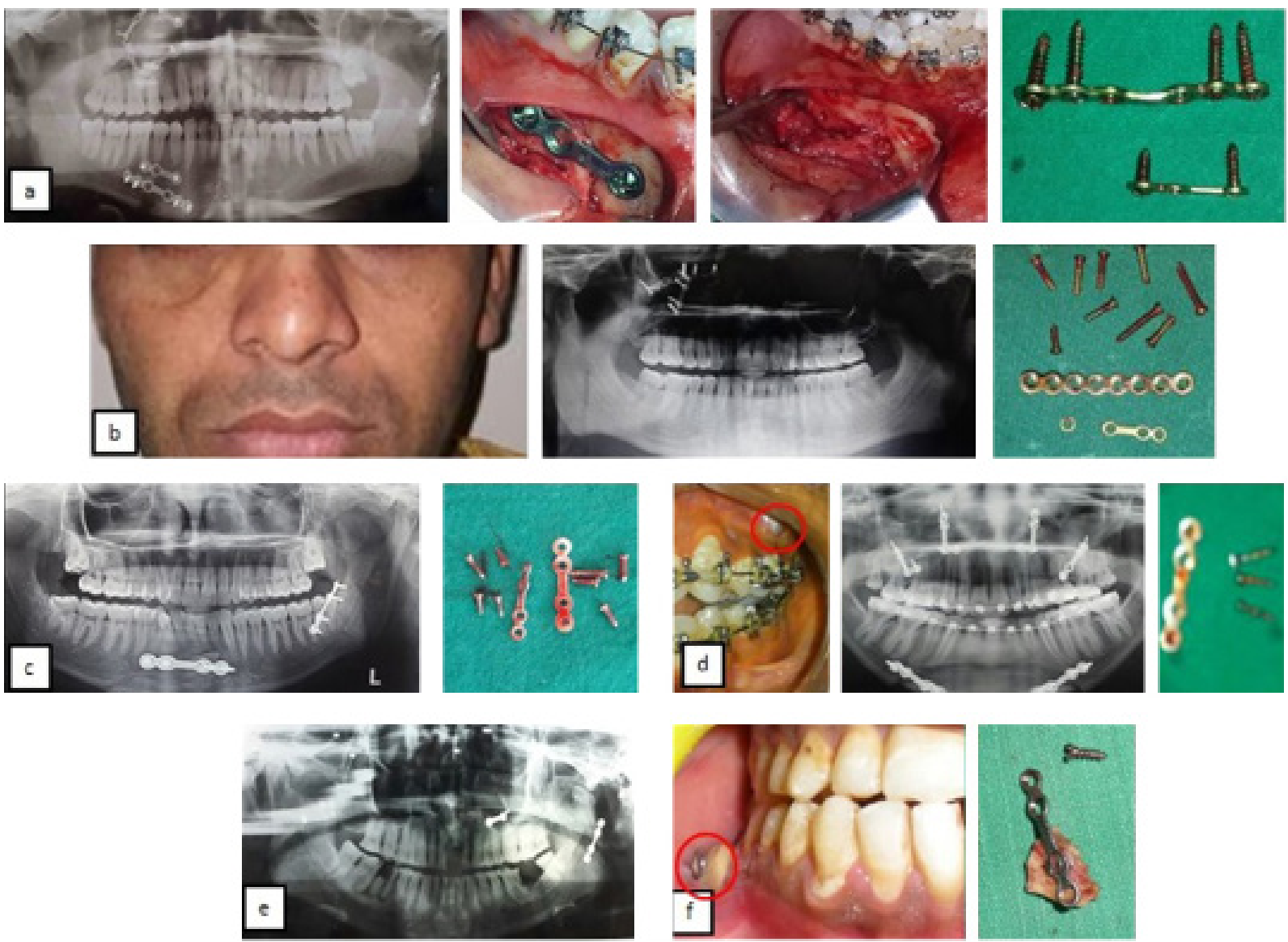

Figure 2. Six cases of pain leading to miniplate removal. a) Pain due to mental nerve compression; b) Pain due to infraorbital nerve compression; c) Pain due to damage to impacted tooth; d) Pain due to palpability (orthognathic surgery case); e) Pain due to malunited condylar fracture; f) Pain due to miniplate exposure.
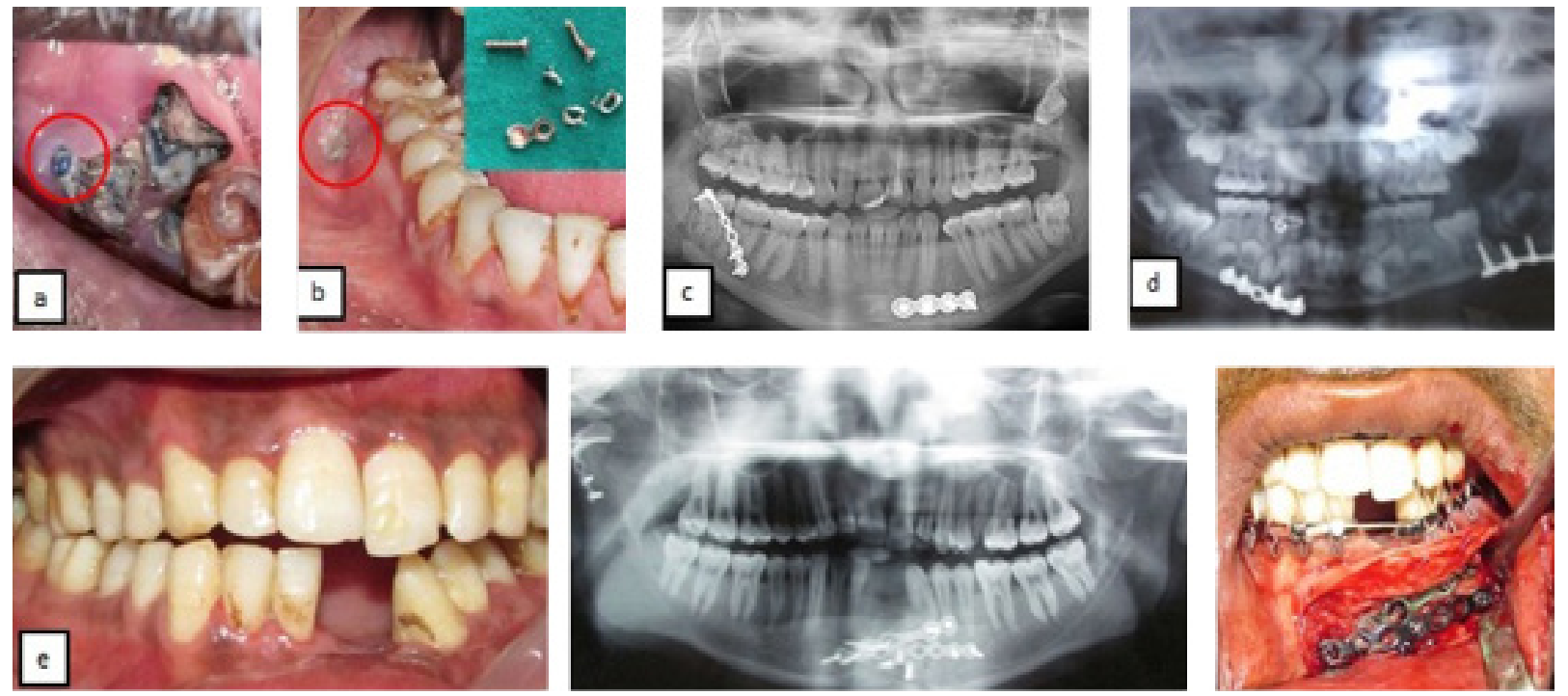

Figure 3. The other five cases of miniplate removal. a) Prosthetic rehabilitation case; b) Asymptomatic miniplate exposure case (cut miniplates and screws in inset); c) Miniplate at angle of mandible region was removed at the patient's request (orthopantomogram); d) Orthopantomogram of 4-year old pediatric patient; e) Malunited symphysis fracture due to inadequate reduction requiring miniplate removal. 
Table V. Pearson correlation between parameters (variables).

\begin{tabular}{l|lc|c} 
S.No. & Variables & Pearson Chi Square value & Sig. \\
a. & Time gap and indication for removal & 9.69 & $0.04^{*}$ \\
b. & Metallic composition and indication for removal & 0.31 & 0.85 \\
c. & Age of patient and indication for removal & 4.48 & 0.61 \\
d. & Number of hardware present and indication for removal & 3.06 & 0.80 \\
e. & Metallic composition and time gap & 0.31 & 0.85
\end{tabular}

(* - Statistically significant)

The association between indications for miniplate removal and time gap was found to be statistically significant $(\mathrm{P}=0.04)$ using Chi-square test. However, correlations between indications for miniplate removal based upon metallic composition, age group and number of miniplates present were non-significant. Correlation between metallic composition of miniplate and time gap for removal was also determined using Chi-square test and found to be non-significant (Table V).

Certain distinctive findings of our study include:

- Osseointegration of the screws was observed in 3 cases, with the impossibility of complete removal (Figure 1a, 3b, 2f).

- Periapical infection was evident in 4 cases (Figure 1a, 1b, 1d, 1g) due to the damage of dental structures.

- In 5 cases, screws were loose as evident on radiographs (Figure 1c, 1e, 1f, 1h, 3e).

- Six cases were having active pus discharge with sinus opening (Figure 1a, 1b, 1d, 1f, 1h, 1i).

- Orthopantomogram in one case (Figure 2e) revealed malunited left condylar fracture with inadequately placed miniplate which led to severe pain in preauricular region. removal.

- Only 1 patient requested asymptomatic miniplate

\section{Discussion}

Several metals have been used since the 1920's for manufacturing hardware for fixation of maxillofacial trauma. Although gold, silver, copper, lead and aluminium were tested, stainless steel emerged through the era as the corrosion resistant material. Later on, at about the same time, titanium gained popularity with advantages over the traditional stainless steel. Titanium was first reportedly used around 1940's and was not only biocompatible metal, it also had tendency for osseointegration and had excellent corrosion resistance. It also had excellent ductility and tensile strength and totally non-toxic [6,7]. Removal of miniplates has remained controversial. According to researchers, who oppose removal of an asymptomatic miniplate, biocompatibility of material, low incidence of complications, the risks of general anesthesia during removal, possible damage to adjacent anatomical structures and the expense of removal contraindicate removal of asymptomatic miniplate. On the contrary, authors who favor removal argue that the miniplate can possibly act as a foreign object with the potential to cause complications, and also miniplates generate growth restrictions among pediatric patients $[8,9]$.

Champy recommended routine removal of all miniplates after 3 months of fixation and this concept became standard [1]. Later, Vitallium gained acceptance as a more inert implant material and authors advocated retention of vitallium miniplates [10]. Frost et al. (1983) studied the fate of vitallium miniplates and reported $18 \%$ removal rate on clinical grounds [11]. Around same time it was shown that titanium (Ti) has startling success in many surgical procedures. According to Meningaud et al., almost $100 \%$ of $\mathrm{Ti}$ is released at local site during the osteosynthesis, however, Ti levels remain constant and stable in the surrounding tissues and remain clinically inert. Removal of Ti miniplates was not accepted as routine procedure except in the case of infection, dehiscence, hypersensitivity or screw loosening [12]. Matthew IR et al. concluded that removal of miniplates and screws should be performed mainly to treat symptoms caused by the implants [13]. Cawood [14] advocated routine removal of stainless steel miniplates after 3 months to prevent interference with jaw function, as miniplates prevent transmission of functional stress to the site, subsequently leading to osteoporosis and weakening of bone. Kennedy [15] also recommended routine removal of miniplates due to stress shielding effect. In a retrospective study of 279 Champy stainless steel miniplates fixed as permanent implants, Brown et al. [1] challenged this practice of routine removal of stainless steel miniplates 3 or 4 months after insertion. Iizuka and Lindqvist [16] routinely removed stainless steel miniplates around one year postoperatively because there were no concepts for leaving a foreign metal object in situ permanently even after the bone had healed. Moberg et al. [17] also advocated removal of nickel-chromium and cobalt-chromium alloy implants after satisfactory bone healing, because metal elements and particles released from the surface may cause allergic sensitization. Rosenberg et al. [18] also removed titanium miniplates only if the patient had complaints. Most studies recommend symptomatic 
miniplate removal and discourage routine removal of asymptomatic miniplates.

The main reason for the removal of the miniplate in our study was infection at the surgical site. In literature also, most common indication reported for miniplate removal is infection involving the site (Table VI). However, Park et al. [8] reported patient demand as most common indication. Miniplates are often located in thin submucosa, which results in exposure to traumatic environmental effects [19]. The masticatory forces acting on the miniplates or screws may compromise interfragmentary stability and consequently, screws may loosen resulting in inflammation which increases the possibility of infection. Poor suturing techniques and inadequate bone cooling during the screw hole preparation have also been suggested as causes of miniplate failure due to infection. Patients receiving injuries in road traffic accidents often have contaminated wounds which increases the incidence for miniplate removal in future $[1,10]$. The infective course associated with miniplates is normally a well localised reaction within the bone and do not develop osteomyelitis or delayed union. Within first 6 weeks after fixation, the infection can be managed conservatively by draining the pus out and antibiotic therapy (local as well as systemic). This permits fracture to heal while the bone remains splinted and fixed. Once the fracture is clinically stable and healed, the miniplate may then be removed. If the infection does not involve underlying operated bone, the existing miniplates can generally be preserved by antibiotics, irrigation, debridement and removal of the nidus, such as a necrotic tooth or soft tissue. However, if infection involves bone and bony union has also not occurred, miniplate removal is indicated which may be followed by external fixation and bone grafting [2]. Tooth damage during fixation surgery or involvement of tooth or teeth in line of fracture at time of trauma led to subsequent development of infection in 4 out of 9 infection-related cases (Figure 1a, 1b, 1d, 1g). In 4 infection cases, screw loosening led to infection (Figure 1c, 1e, 1f, 1h). Impaired healing due to compromised blood supply in edentulous mandible might have led to infection in 1 remaining case (Figure 1i).

Mosbah et al. [9] reported 14\% incidence of pain after surgery at or around site of fixation, whereas Bhatt et al. [4] reported pain in $24 \%$ cases. In our study, pain was reported to be the cause of miniplate removal in 6 patients $(30 \%)$. Pain was subsequent to nerve compression by miniplate in two cases; tooth damage, miniplate palpability, malunited condylar fracture and miniplate exposure in one case each. Other symptoms or conditions contributing for miniplate removal include patient request, pediatric growth restriction, prosthetic rehabilitation, miniplate exposure, deformities due to malunion or non-union, tooth extraction, screw loosening, wound dehiscence, palpability, nerve damage, cold intolerance, etc. In our study, only one patient requested asymptomatic miniplate removal and rest of the hardware removal were performed subsequent to associated hardware complications.

In pediatric patients, miniplates should be removed within two to three months after fracture surgery due to the potential of growth restriction [20,21]. In a four year retrospective study by Burlini et al. [22], 912 pediatric patients underwent treatment by conventional methods using metal fixation for maxillofacial fractures. All patients underwent a second surgery to remove the nonresorbable materials $6-8$ months after the first surgery to prevent long-term growth disturbance. However, according to Cole et al. [23], there is no absolute reason for routine removal of fixation devices in children and a second procedure for removal should be performed only in cases where the hardware is symptomatic. Our study reported higher removal rate $(75 \%)$ among patients younger than 40 years of age. In a study conducted by Park et al. [8], 60\% patients who underwent miniplate removal were younger than 30 years of age. As age increased, the removal rate was found to decrease. This is in slight contrast with the results of a previous study, which has found that the removal rate of miniplates is high among patients aged 30 years or older [18].

Table VI. Comparison with other studies.

\begin{tabular}{|c|c|c|c|c|c|c|c|}
\hline Studies & $\begin{array}{l}\text { No. of } \\
\text { patients } \\
\text { studied }\end{array}$ & $\begin{array}{l}\text { No. of } \\
\text { year } \\
\text { study }\end{array}$ & $\begin{array}{l}\text { Most common indication } \\
\text { for miniplate removal }\end{array}$ & Time gap & $\begin{array}{l}\text { No. of } \\
\text { miniplates } \\
\text { removed }\end{array}$ & $\begin{array}{c}\text { Recommendation for } \\
\text { routine asymptomatic } \\
\text { miniplate removal }\end{array}$ & $\begin{array}{l}\text { Removal } \\
\text { rate }(\%)\end{array}$ \\
\hline Park et al. [8] & 120 & 5 & Patient demand $(81.7 \%)$ & 1 year $(80 \%)$ & - & Not indicated & 22.6 \\
\hline Bhatt et al. [4] & 21 & 4 & Infection $(50 \%)$ & 1 year $(72 \%)$ & 32 & Not indicated & - \\
\hline Islamoglu K [19] & - & 7 & $\begin{array}{l}\text { Infection }(28.57 \%) \text {; } \\
\text { Extrusion }(24.28 \%)\end{array}$ & 3 months -14 months & - & Not indicated & 7 \\
\hline O’Connell J [30] & 30 & 10 & Infection $(41 \%)$ & 1 year (most cases) & 32 & Not indicated & 3 \\
\hline Rallis et al. [3] & 27 & - & Infection and exposure & - & 37 & Not indicated & 6.17 \\
\hline Mosbah et al. [9] & - & 2 & $\begin{array}{l}\text { Infection and/or wound } \\
\text { dehiscence }\end{array}$ & - & - & Not indicated & 10 \\
\hline
\end{tabular}


With regard to the length of time from first surgery to miniplate removal, most cases (45\%) involved removal within one year. Majority of the miniplate removal, as reported in the literature, occurred within 6 months to 1 year of fixation (Table VI). A few authors even reported miniplate removal at less than 3 months of fixation [2]. Routine removal of the miniplates should be performed after confirmation of bone healing and principally should be performed between 6 months and a year [24]. Most of the miniplates $(80 \%)$ were removed from mandible. Removal of the miniplate from the mandible was most often performed at the mandibular body and symphysis region. Park et al. [8] concluded that mandibular angle region is most common site for miniplate removal (39.5\%). Islamoglu K [19] reported $62.85 \%$ incidence of involvement of mandible for hardware removal in maxillofacial region.

Matthew et al. [25] conducted low-vacuum scanning electron microscopy (SEM) and concluded that no distinguishable difference exists in the surface characteristics of either stainless steel or titanium miniplates removed at 4, 12 and 24 weeks after surgery. Energy-dispersive X-ray (EDX) identified aluminium and silicon deposits over the flat surfaces of these miniplates. Hence, it was not evident to support the routine removal of either titanium or stainless steel miniplates subsequent to surface corrosion up to 6 months after implantation [25]. In the biologic environment, stainless steel degrades by combination of electrochemical corrosion and wear and titanium degrades mainly due to wear and particle release. Corrosion and wear products (metal ions or particles) may lead to changes in the surrounding tissues, ranging from fibrosis to infection and necrosis [26]. Because of associated complications like corrosion, toxicity, hypersensitivity and stress protection, stainless steel should not be considered as a permanent fixation device in maxillofacial region. However, due to the absence of any untoward reaction of bone and soft tissues, superior corrosion resistance, non-carcinogenicity, hyposensitivity, nontoxicity and excellent tissue compatibility, the removal of titanium hardware, subsequent to their fixation, can be harmlessly avoided and can be retained as permanent implants in maxillofacial region [27]. Venable et al. [28] also reported osteolysis and necrosis around stainless steel implants due to electrolysis. However, we found that the role of metallic composition (either stainless steel or titanium) is negligible as number of miniplates removed were equal for stainless steel and titanium metal. Intraoperatively, we encountered osseointegration of screws in three cases wherein the metallic composition of hardware was titanium. Linder and Lundskog found that the bone formed around the titanium screws was dense, which might cause difficulty in retrieving the titanium screws being firmly adherent [29].

We found co-relations between indications for miniplate removal based upon time gap, metallic composition, age group and number of miniplates present; and correlation between metallic composition of miniplate and time gap for removal was also determined using Chisquare test (Table $\mathrm{V})$. The association between indications for miniplate removal and time gap was found to be statistically significant $(P=0.04)$. It was signified that time gap had a major role in development of specific symptoms. Infection was the common indication for miniplate removal within a time gap of $1-2$ years. After two years of miniplate fixation, pain and infection led to miniplate removal. Within one year of miniplate placement, other factors were prevalent which led to miniplate removal. However, association between indications for miniplate removal and metallic composition; age group; and number of miniplates present were non-significant. Metallic composition of miniplate, age of patient and number of hardware fixed in first surgery had no role in development of causative factors like pain, infection, etc. Correlation between metallic composition of miniplate and time gap for removal was also determined using Chi-square test and found to be non-significant.

\section{Conclusion}

Complications are equally associated with stainless steel miniplates as well as titanium ones and hence, the role of metallic composition (either stainless steel or titanium) is negligible. Routine asymptomatic miniplates do not require removal, however, miniplate removal should be performed when hardware is causing various complications and physical symptoms. Infection, miniplate exposure, pain, palpability or any other morbidity that appears after bony union should be treated by miniplate removal. There is a need for further study and research on the management of maxillofacial hardware complications before bony union occurs.

\section{Acknowledgement}

Authors acknowledge the contribution of Dr. Soni Rajput (MDS - Public Health Dentistry) for statistical analysis and review of the data.

\section{References}

1. Brown JS, Trotter M, Cliffe J, Ward-Booth RP, Williams ED. The fate of miniplates in facial trauma and orthognathic surgery: a retrospective study. Br J Oral Maxillofac Surg. 1989;27:306-315.

2. Hernandez Rosa J, Villanueva NL, Sanati-Mehrizy P, Factor SH, Taub PJ. Review of Maxillofacial Hardware Complications and Indications for Salvage. Craniomaxillofac Trauma Reconstr. 2016;9:134-140.

3. Rallis G, Mourouzis C, Papakosta V, Papanastasiou G, Zachariades N. Reasons for miniplate removal following maxillofacial trauma: a 4-year study. J Craniomaxillofac Surg. 2006;34:435-439.

4. Bhatt V, Chhabra P, Dover MS. Removal of miniplates in 
maxillofacial surgery: a follow-up study. J Oral Maxillofac Surg. 2005;63:756-760.

5. Murthy AS, Lehman JA Jr. Symptomatic plate removal in maxillofacial trauma: a review of 76 cases. Ann Plast Surg. 2005;55:603-607.

6. Deepak S, Manjula S. Comparison of Titanium bone plates and screws vs. stainless steel bone plates and screws in the management of mandibular fractures - A long term clinical study. Int. Journal of Clinical Dental Science. 2011;2:38-43.

7. Roberts WR. The case for mandibular plating. Br J Orol Surg. 1964;1:200-204.

8. Park HC, Kim SG, Oh JS, You JS, Kim WG. Mini-plate removal in maxillofacial trauma patients during a five-year retrospective study. J Korean Assoc Oral Maxillofac Surg. 2016;42:182-186.

9. Mosbah MR, Oloyede D, Koppel DA, Moos KF, Stenhouse D. Miniplate removal in trauma and orthognathic surgery--a retrospective study. Int J Oral Maxillofac Surg. 2003;32:148151.

10. Michelet FX, Deymes J, Dessus B. Osteosynthesis with miniaturized screwed plates in maxillo-facial surgery. J Maxillofac Surg. 1973;1:79-84.

11. Frost DE, El-Attar A, Moos KF. Evaluation of metacarpal bone plates in the mandibular fracture. Br J Oral Surg. 1983;21:214-221.

12. Meningaud JP, Poupon J, Bertrand JC, Chenevier C, GalliotGuilley M, Guilbert F. Dynamic study about metal release from titanium miniplates in maxillofacial surgery. Int J Oral Maxillofac Surg. 2001;30:185-188.

13. Matthew IR, Frame JW. Policy of consultant oral and maxillofacial surgeons towards removal of miniplate components after jaw fracture fixation: pilot study. Br J Oral Maxillofac Surg. 1999;37:110-112.

14. Cawood JI. Small plate osteosynthesis of mandibular fractures. Br J Oral Maxillofac Surg. 1985;23:77-91.

15. Kennedy MC, Tucker MR, Lester CE, Buckley MJ. Stress shielding effect of rigid internal fixation plates on mandibular bone grafts. A photon absorption densitometry and quantitative computerized tomographic evaluation. Int $\mathrm{J}$ Oral Maxillofac Surg. 1989;18:307-310.

16. Iizuka $T$, Lindqvist $C$. Rigid internal fixation of mandibular fractures. An analysis of 270 fractures treated using the $\mathrm{AO} /$ ASIF method. Int J Oral Maxillofac Surg. 1992;21:65-69.

17. Moberg LE, Nordenram A, Kjellman O. Metal release from plates used in jaw fracture treatment. A pilot study. Int J Oral Maxillofac Surg. 1989;18:311-314.

18. Rosenberg A, Grätz KW, Sailer HF. Should titanium miniplates be removed after bone healing is complete? Int $\mathrm{J}$ Oral Maxillofac Surg. 1993;22:185-188.

19. Islamoglu K, Coskunfirat OK, Tetik G, Ozgentas HE. Complications and removal rates of miniplates and screws used for maxillofacial fractures. Ann Plast Surg. 2002;48:265-268.

20. Haug RH, Cunningham LL, Brandt MT. Plates, screws, and children: their relationship in craniomaxillofacial trauma. J Long Term Eff Med Implants. 2003;13:271-287.

21. Zimmermann CE, Troulis MJ, Kaban LB. Pediatric facial fractures: recent advances in prevention, diagnosis and management. Int J Oral Maxillofac Surg. 2006;35:2-13.

22. Burlini D, Conti G, Amadori F, Bardellini E, De Giuli C. Management of paediatric maxillofacial fractures: conventional methods and resorbable materials. Eur J Paediatr Dent. 2015;16:24-28.

23. Cole P, Kaufman Y, Hollier LH Jr. Managing the pediatric facial fracture. Craniomaxillofac Trauma Reconstr. 2009;2:77-84.

24. Yamamoto K, Matsusue Y, Horita S, Murakami K, Sugiura T, Kirita T. Routine removal of the plate after surgical treatment for mandibular angle fracture with a third molar in relation to the fracture line. Ann Maxillofac Surg. 2015;5:77-81.

25. Matthew IR, Frame JW, Browne RM, Millar BG. In vivo surface analysis of titanium and stainless steel miniplates and screws. Int J Oral Maxillofac Surg. 1996;25:463-468.

26. Torgersen S, Gjerdet NR. Retrieval study of stainless steel and titanium miniplates and screws used in maxillofacial surgery. J Mater Sci: Mater Med. 1994;5:256-262.

27. Haug RH. Retention of asymptomatic bone plates used for orthognathic surgery and facial fractures. J Oral Maxillofac Surg. 1996;54:611-617.

28. Venable CS, Stuck WG, Beach A. The effects on bone of the presence of metals; based upon electrolysis: an experimental study. Ann Surg. 1937;105:917-938.

29. Linder L, Lundskog J. Incorporation of stainless steel, titanium and Vitallium in bone. Injury. 1975;6:277-285.

30. O'Connell J, Murphy C, Ikeagwuani O, Adley C, Kearns G. The fate of titanium miniplates and screws used in maxillofacial surgery: a 10 year retrospective study. Int J Oral Maxillofac Surg. 2009;38:731-735. 